Hydrology and Earth System Sciences, 2(4), 473-483 (1998) C EGS

\title{
Comparison of simulated forest soil response to acid deposition reduction with two models of differing complexity
}

\author{
Janet P. Mol-Dijkstra, Hans Kros and Caroline van der Salm \\ DLO-Winand Staring Centre for Integrated Land, Soil and Water Research (SC-DLO), P.O. Box 125, NL-6700 AC Wageningen
}

\begin{abstract}
Great effort has been dedicated to developing soil acidification models for use on different scales. This paper focuses on the changes in model performance of a site scale soil acidification model (NUCSAM) and a national to European scale soil acidification model (SMART 2). This was done to gain insight into the effects of model simplification. Because these models aim to predict the response to reduction in acid deposition, these models must be tested under such circumstances. A straightforward calibration and validation of the regional model, however, is hampered by lack of observations over a sufficient time period. Consequently, NUCSAM was calibrated and validated to a manipulation experiment involving reduced acid deposition in the Speuld forest, the Netherlands. SMART 2 was then used with calibrated input data from NUCSAM. The acid deposition was excluded by a roof beneath the canopy. The roofed area consists of a plot receiving pristine deposition levels of nitrogen (N) and sulphur (S) and a control plot receiving ambient deposition. NUCSAM was calibrated on the ambient plot, followed by a validation of both models on the pristine plot.

Both models predicted soil solution concentrations within the $95 \%$ confidence interval of the observed responses for both the ambient plot and the pristine plot at $90 \mathrm{~cm}$ depth. Despite the large seasonal and vertical (spatial) variation in soil solution chemistry, the trends in annual flux-weighted soil solution chemistry, as predicted by SMART 2 and NUCSAM, corresponded well. The annual leaching fluxes below the root zone were also similar although differences exist for the topsoil. For the topsoil, NUCSAM simulated the nutrients and acid related constituents better than SMART 2. Both models overestimated the ammonium $\left(\mathrm{NH}_{4}\right)$ concentration at $10 \mathrm{~cm}$ depth. SMART 2 underestimated calcium and magnesium $\left(\mathrm{BC}^{2+}\right)$ concentration at 10 depth, whereas NUCSAM overestimated $\mathrm{BC}^{2+}$ concentration at $90 \mathrm{~cm}$ depth. NUCSAM predicted the effect of deposition reduction on $\mathrm{N}$ concentrations at both depths, whereas SMART 2 underestimated the effect of deposition reduction at $10 \mathrm{~cm}$ depth. Both models predicted faster effects of deposition reduction on aluminium $(\mathrm{Al})$, sulphate $\left(\mathrm{SO}_{4}\right)$ and base cations than was observed. Generally, it appeared that the differences were large during the period of profound deposition changes whereas small differences occurred during slight variations in deposition level. It is concluded that a simpler model description does not affect the model's performance significantly as regards flux-weighted annual average concentrations at greater depth. Model improvements must focus on processes related to $\mathrm{N}$-dynamics.
\end{abstract}

\section{Introduction}

Soil and catchment acidification models are widely used at local to continental scale for assessing effects of reduction of emissions of acidifying compounds. In the Netherlands, for example, NUCSAM, a complex local scale model including seasonal variability (Groenenberg et al., 1995) contributes insight into acidification processes at the local scale and short time-scales. To simulate the seasonal dynamics at a local scale adequately, NUCSAM includes relatively complex and detailed process formulations. The site scale properties enable calibration at intensive monitoring sites. SMART 2, a relatively simple regional scale model which neglects seasonal variability (Kros et al., 1995b), has been developed for application at the regional scale (ranging from region to continent). A major aim of SMART 2 is to predict long-term effects of deposition scenarios at regional scale. To minimize data requirements for applications at larger scales, SMART 2 is relatively simple and has a high degree of process aggregation. Model simplifications include (i) temporal aggregation of processes, (ii) vertical and spatial aggregation of soil layers and (iii) aggregation of process descriptions. These simplifications may cause errors in long-term predictions. Seasonal variability is generally driven by climatic (e.g. precipitation, deposition, evaporation, snowmelt) and biotic factors (e.g. litterfall, mineralization, nutrient 
uptake). A comparison of the simple (SMART 2) with the complex (NUCSAM) model using the same data set provides insight into the effects of model simplification in terms of the required output of the simpler regional scale model.

Validation of regional scale models is hampered by lack of long-term observations on the effects of reduction in deposition. If observations are available, they are usually related only to an individual plot or a small catchment. Large scale models are tested mainly on short data series of about 5 years. A notable exception is the Solling site in Germany with data series from 1973 (major ion concentrations at $90 \mathrm{~cm}$ depth); this was used for the calibration of SMART 2 (Van der Salm et al., 1995) as well as MAGIC (Alewell et al., 1997). Recently, the possibilities for validation have been increased by results from longterm ecosystem manipulation experiments, e.g. in Norway (Wright et al., 1990), the Netherlands (Boxman et al., 1995) and Sweden (Giesler et al., 1996). These manipulation experiments are valuable for model validation and assessment leading to model improvement.

These problems led to the two main objectives of this study. The first is to evaluate whether a simplified regional-scale model can be used for national to continental assessments of the effect of emission reduction. In other words, what are the effects on long-term predictions of model simplification by neglecting seasonal variability and vertical heterogeneity. The second objective is to identify weak elements in the models and the observation data, which may lead to a better understanding of the ecosystem and, hence, model improvement.

In the present study, a comparison was made between the performance of NUCSAM and SMART 2 to the roofed ecosystem manipulation experiment at Speuld, the Netherlands. The roofed area consists of a plot receiving pristine (pre-industrial) deposition levels of $\mathrm{N}$ and $\mathrm{S}$ and a control plot receiving ambient deposition. Because the observation records are collected at a plot scale over a relatively short period of time, these data cannot be used for a straightforward validation of the regional scale model SMART 2 that uses an annual time step. Although a comparable large scale model like MAGIC (Beier et al., 1995 and Cosby et al., 1995) has been applied with relatively short periods of observations to different sites with promising results. In addition, these applications are focussed on small catchments, where output concentrations are the average of the whole catchment. To handle the time-scale and spatial scale problems, NUCSAM was calibrated at the Speuld site whilst SMART 2 was used afterwards, using calibrated input data from NUCSAM, to examine whether SMART 2 gave results comparable to NUCSAM at the relevant time-scale and to see how both models reacted to reductions in deposition. NUCSAM was calibrated to the ambient plot, whereas SMART 2 was fed with parameters resulting from the NUCSAM calibration. Subsequently, both models were validated to the manipu- lation plot with pristine deposition to identify weak elements in the models.

The calibration of NUCSAM has been described elsewhere (Van der Salm et al., this issue). Here, an application of SMART 2 is presented using the results of the NUCSAM calibration followed by a comparison of calculated concentrations and annual fluxes with those predicted by NUCSAM.

\section{Models}

Both NUCSAM and SMART 2 simulate the major biogeochemical processes in the canopy, litter layer and mineral soil horizons. The differences between SMART 2 and NUCSAM concern the spatial and temporal scale and the complexity of the process description. Unlike SMART 2, NUCSAM is applicable on a local scale, since it simulates solute transport and biogeochemical processes on a daily timestep, while SMART 2 uses a yearly timestep. Consequently, NUCSAM accounts for seasonal variation in deposition, precipitation, transpiration, litterfall, mineralization and root uptake, and all the biochemical and geochemical processes are modelled as a function of temperature whereas SMART 2 neglects these effects. Furthermore, SMART 2 treats the mineral soil layer as one compartment, while NUCSAM distinguish multiple soil layers. To compare both models at the same time scale, the NUCSAM output is averaged over the soil layers and over the year.

\section{THE SMART 2 MODEL}

SMART 2 (Kros et al., 1995a) is a simple one-compartment soil acidification and nutrient cycling model that includes the major hydrological and biogeochemical processes in the vegetation, litter and mineral soil. Apart from $\mathrm{pH}$, the model also predicts changes in aluminium $\left(\mathrm{Al}^{3+}\right)$, base cation $(\mathrm{BC})$, nitrate $\left(\mathrm{NO}_{3}{ }^{-}\right)$and sulphate $\left(\mathrm{SO}_{4}{ }^{2-}\right)$ concentrations in the soil solution and solid phase characteristics depicting the acidification status, i.e. carbonate content, base saturation and readily available $\mathrm{Al}$ content. SMART 2 is an extension of the dynamic soil acidification model SMART (De Vries et al., 1989). The major enhancements in SMART 2 are the inclusion of a nutrient cycle and an improved modelling of hydrology. SMART 2 consists of a set of mass balance equations, describing the soil input-output relationships, and a set of equations describing the rate-limited and equilibrium soil processes.

The soil solution chemistry in SMART 2 depends solely on the net element input from the atmosphere (the product of deposition and canopy filtering factor) and groundwater (seepage), canopy interactions (foliar uptake, foliar exudation), geochemical interactions in the soil $\left(\mathrm{CO}_{2}\right.$ equilibria, weathering of carbonates, silicates and/or Alhydroxides, $\mathrm{SO}_{4}{ }^{2-}$ sorption and cation exchange) and a 
complete nutrient cycle (litterfall, mineralization, root uptake, immobilization, nitrification and denitrification) for basic cations and N. Litterfall and growth of the vegetation are modelled by a logistic growth function which acts as a forcing function for nutrient uptake. Nutrient uptake is limited only when there is a shortage in the soil solution. Processes that are not taken into account, are (i) $\mathrm{N}$ fixation and $\mathrm{NH}_{4}{ }^{+}$adsorption, (ii) uptake, immobilization and reduction of $\mathrm{SO}_{4}^{2-}$, (iii) complexation of $\mathrm{Al}^{3+}$ with hydroxide $\left(\mathrm{OH}^{-}\right), \mathrm{SO}_{4}{ }^{2-}$ and organics $\left(\mathrm{RCOO}^{-}\right)$.

Soil interactions are described either by simple ratelimited (zero-order) reactions (uptake and silicate weathering) or by equilibrium reactions (carbonate and Alhydroxide weathering and cation exchange). Influences of environmental factors such as $\mathbf{p H}$ and moisture content are included for mineralization, nitrification and denitrification, but not for weathering and exchange reactions. Solute transport is described by assuming complete mixing of the element input within one homogeneous soil compartment with a constant density and a fixed depth, since SMART 2 is a single layer soil model and neglects vertical heterogeneity. It predicts the concentration of the soil water leaving the root zone. The annual water flux percolating from this layer is set equal to the annual precipitation minus the evapotranspiration, and is specified as model input. The time step of the model is one year so seasonal variations are not considered. De Vries et al. (1989) justify the various assumptions and simplifications.

Recently, SMART 2 was extended to a two-compartment model; an organic layer and a mineral layer. Because the original SMART 2 model predicts $\mathrm{pH}$ values that depend on the thickness of the soil compartment, different $\mathrm{pH}$ reduction factors for mineralization, nitrification and denitrification result. In the two-compartment version, these reduction factors are related to the $\mathrm{pH}$ values in the organic layer, which has a constant thickness. Nitrification, denitrification, weathering, transpiration and root uptake were divided over the two layers by assigning fractions for the humus layer and mineral layer summing up to 1.0 . This extended version of SMART 2 was used in this application.

\section{THE NUCSAM MODEL}

NUCSAM (Groenenberg et al., 1995), derived from RESAM (De Vries et al., 1995), also simulates the major biogeochemical processes in the forest canopy, litter layer, and mineral soil but the temporal resolution is daily. Consequently, hydrological processes are also included, i.e. (i) partitioning of precipitation into rainfall and snowfall, (ii) snowpack accumulation and snowmelt, (iii) interception evaporation from the forest canopy, (iv) soil evaporation and transpiration, and (v) one-dimensional vertical transient water flow. Water fluxes and soil water contents are calculated with an adapted version of the SWATRE (Belmans et al., 1983) model. The biogeochemical processes accounted for in the model are basically the same as those in SMART 2. In contrast to SMART 2, however; (i) mineralization in the organic layer is extended to three compartments ( $\mathrm{L}, \mathrm{F}$ and $\mathrm{H}$ layer); (ii) litterfall, root decay, mineralization and root uptake are distributed over the year by monthly coefficients; (iii) nutrient cycling also includes $\mathrm{SO}_{4}$, and (iv) carbonate and Al-hydroxide weathering are described by rate-limited reactions. All chemical equilibrium and rate limited equations are solved with a separate chemical equilibrium module which allows for the calculation of aluminium speciation by considering hydrolysis reactions and complexation with organic and inorganic anions. In this study, a slightly adapted version of NUCSAM was used, in which the N-content in the needles was kept constant. The original version of NUCSAM used a relationship between $\mathrm{N}$-deposition and $\mathrm{N}$ content in the needles. This led to a substantial underestimate of the N-uptake upon a reduction of $\mathrm{N}$ deposition (Van der Salm et al., 1998).

\section{Methodology}

\section{MANIPULATION EXPERIMENT AND INPUT DATA}

The two models were applied to an acid deposition exclusion experiment in a 40 year old Douglas fir plantation in the Netherlands (Boxman et al., 1995; Van der Salm et al., 1998). In 1989, a $2-3 \mathrm{~m}$ high transparent roof was erected to intercept throughfall before it reached the forest floor. Part of the roofed area received ambient deposition whereas the other part received deposition with pristine amounts of $\mathrm{N}$ and $\mathrm{S}$. Until 1992, the collected throughfall was sprinkled every two weeks. This system was replaced by almost real time watering in February 1992. As described in Boxman et al. (1995). Ceramic lysimeter cups were installed in the mineral soil of each plot at depths of $10 \mathrm{~cm}$ (eight replicates), $25 \mathrm{~cm}$ (four replicates), $45 \mathrm{~cm}$ (four replicates) and $90 \mathrm{~cm}$ (four replicates). Boxman et al. (1995) analysed only the averaged value of the replicates and paid no attention to the strong spatial variation among them. Van der Salm et al. (this issue), however, calculated 95\% confidence intervals per plot for each observation date from 1990-1994 and found strong fluctuations in soil solution between the individual cups in both the roofed plot with ambient and with pristine deposition. The coefficient of variation ranged between 30 and $150 \%$. Accordingly, the $95 \%$ confidence interval around the measurements was rather broad, especially in dry periods when no soil solution could be extracted from some of the cups. Moreover, the lack of soil solution data from these cups, situated in the dryer part of the plot may lead to an underestimation of the average concentrations during these dry periods.

Model input data for NUCSAM and SMART 2 were derived from monitoring data for the roofed site and from 
data gathered in nearby parts of the Speuld forest. An extensive description of the data derivation for the NUCSAM application is given by Van der Salm et al. (this issue). Hydrological fluxes and water contents were calculated by SWATRE (Belmans $e t$ al., 1983; Groenenberg $e t$ al., 1995). The averaged calculated drainage fluxes over 1991 and 1992 were 366 and 143 at $10 \mathrm{~cm}$ and $90 \mathrm{~cm}$ depth respectively. These fluxes are larger than the averaged fluxes over 1991 and 1992 calculated by an alternative model, NICCE (Boxman et al., 1995) $(270 \mathrm{~mm}$ and 100 $\mathrm{mm}$ at $10 \mathrm{~cm}$ and $90 \mathrm{~cm}$ respectively). This difference is caused by using the calculated throughfall water fluxes from the ambient control plot (not roofed) to the roofed plot (Van der Salm et al., 1998). Deposition throughfall fluxes were based on the composition of the solution sprinkled under the roof. Growth rates, turnover rates and nutrient contents of the biomass were based on measurements in the Speuld forests. Mineralization rates were calibrated on the thickness of the forest floor. Most geochemical parameters and rate constants were taken from a previous application of NUCSAM in another part of the Speuld forest (Tiktak et al., 1995). Cation exchange capacity (CEC), adsorbed base cations and Gaines-Thomas exchange constants were, however, based on measurements in 1992 on the roofed plot. Sulphate adsorption capacity, although small, was calibrated on the observed $\mathrm{SO}_{4}$ concentrations.

\section{INPUT MAPPING}

To compare the two models, the input data had to be derived so that both models start under similar conditions. The difference in temporal and spatial detail between the two models requires tuning of input data and model parameters to each model. The set of rules and algorithms that transform information into specific input values, is called input mapping (Rose et al., 1991).

Input-mapping was applied to the water fluxes, throughfall fluxes, weathering, and the following processes: cation exchange, C-mineralization, and growth to the vegetation parameters. Processes such as nitrification and denitrification were kept out of the input mapping procedure. The throughfall and water fluxes for SMART 2 were derived by accumulating the daily values that were used in NUCSAM. SWATRE was applied to the roofed ambient plot only. This means that the same fluxes were used for both the ambient and the pristine plot. Vegetation parameters were set equal to those in NUCSAM, such as: initial age of the stand, growth curve, litterfall, foliar uptake and minimum and maximum contents of nutrients in the various biomass compartments. In contrast to the usual calculation of foliar uptake by SMART 2 as a fraction of the deposition, the foliar uptake flux calculated by NUCSAM was taken as input. The Gaines-Thomas selectivity constants were derived from observations from 1992, since both soil solution concen- trations and the composition of the exchange complex were measured together. Firstly, the concentrations were depth-weighted and the exchange complex compositions were bulk density-weighted. The averaged concentrations and exchange complex compositions were used to calculate the Gaines-Thomas selectivity constants. At $10 \mathrm{~cm}$ depth, the Gaines-Thomas selectivity constants had comparable values (-1.8 in SMART 2 and -1.7 in NUCSAM for the selectivity constant for $\mathrm{Al}^{3+} / \mathrm{BC}^{2+}$ exchange, and 3.7 in SMART 2 and 3.5 in NUCSAM for the selectivity constant for $\mathrm{H}^{+} / \mathrm{BC}^{2+}$ exchange). At $90 \mathrm{~cm}$ depth, the selectivity constant for $\mathrm{Al}^{3+} / \mathrm{BC}^{2+}$ exchange was 3.9 in SMART 2 and between 3.4 and 3.6 in NUCSAM. The selectivity constant for $\mathrm{H}^{+} / \mathrm{BC}^{2+}$ exchange at this depth was -1.7 in SMART 2 and -0.2 to -1.7 in NUCSAM. The same procedure was adopted for the derivation of the weathering rates and the dissolution constant for Alhydroxide, but with measured soil solution concentrations from 1990 to 1994 . The averaged concentrations over the years were calculated and after that the concentrations over depth were calculated. The mineralization rate constant of old litter in SMART 2 was calibrated to the amount of litter in terms of C calculated by NUCSAM. Since nitrification and denitrification parameters were kept out of input-mapping, standard values for sandy soils were used (Kros et al., 1995a).

\section{MODEL COMPARISON}

NUCSAM was calibrated to the roofed plot with ambient deposition (Van der Salm, this issue). The validation was performed by an application to the pristine plot using the hydrology and parameters from the ambient plot and the reduced throughfall level. For the comparison with SMART 2, the annual flux-weighted average soil solution concentrations of NUCSAM were used, calculated by dividing the total annual element fluxes by the total annual water fluxes. To compare the model results with the data, the measured concentrations were aggregated accordingly towards flux-weighted annual averages, using the simulated water fluxes. The plot average water fluxes, calculated by SWATRE, may deviate substantially from fluxes at the individual cups. Since only a few samples were taken in 1990 and 1991, it was not possible to calculate satisfactory annual means. Therefore, only the results of 1992-1994 are presented. The calculation of the annual flux-weighted averages was done for each cup per depth (eight at $10 \mathrm{~cm}$ and four at $90 \mathrm{~cm}$ depth). Afterwards, the $95 \%$ confidence intervals of the annual means were calculated using the results of the individual cups. As with the individual concentrations, large $95 \%$ confidence intervals were found (Figs. 1 and 2).

Initialisation of SMART 2 was performed by using an initialisation period of ten years. The initial base saturation was derived from the measurements of 1992 , i.e. $10 \%$. For other model inputs whose estimation was based on 
$10 \mathrm{~cm}$
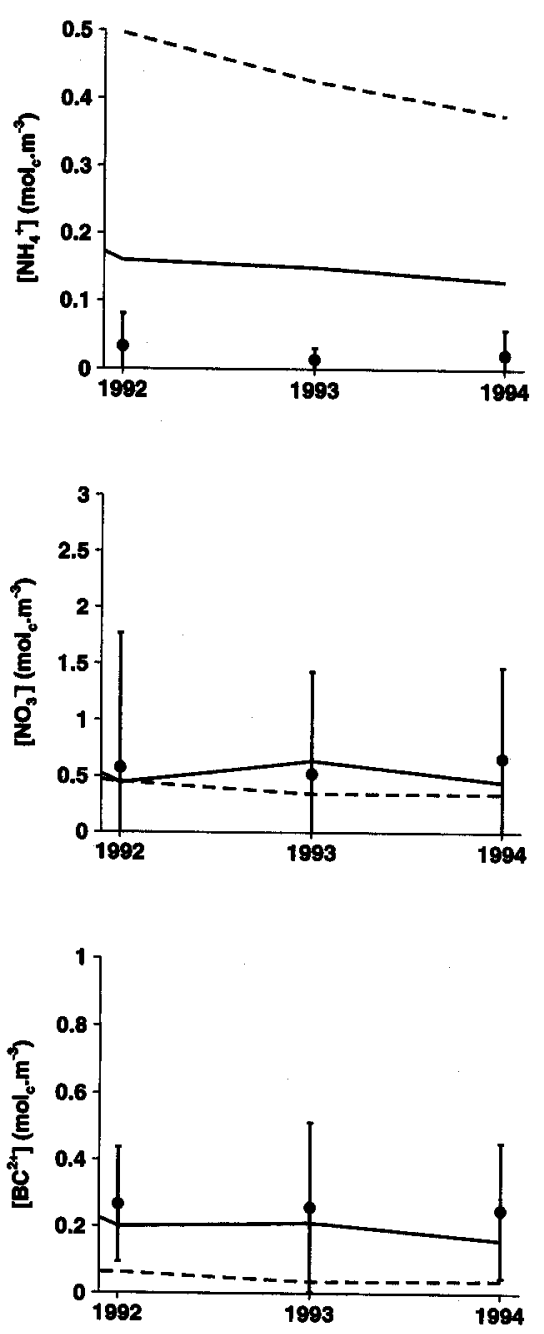

$90 \mathrm{~cm}$
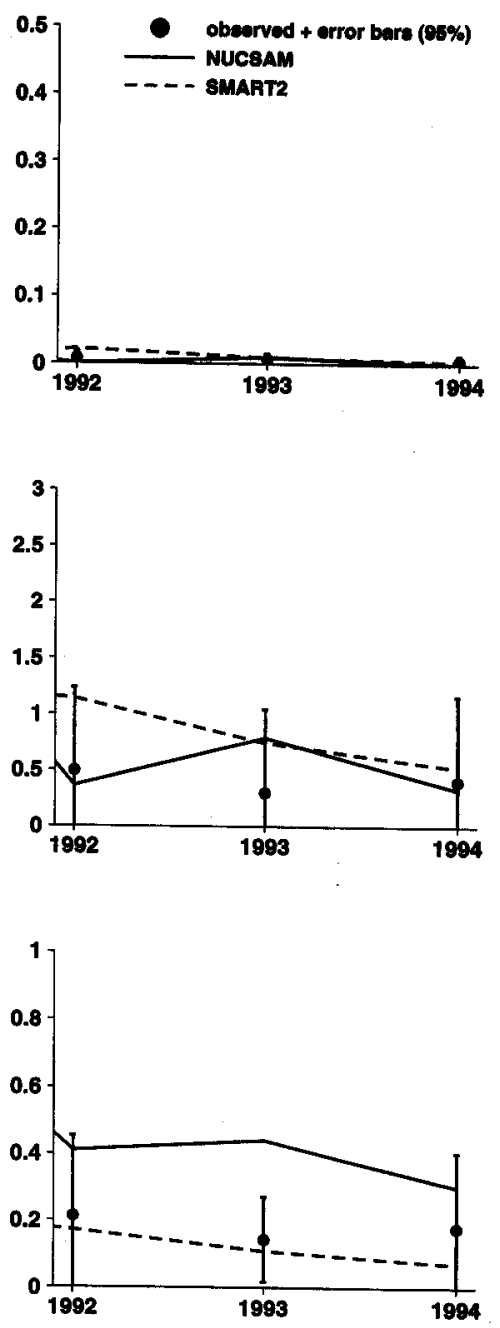

Fig. 1. Simulated and observed flux-meighted annual average concentrations of $\mathrm{NH}_{4}^{+}, \mathrm{NO}_{3}^{-}$and $\mathrm{BC}^{2+}\left(\mathrm{Ca}^{2+}+\mathrm{Mg}^{2+}\right)$ at $10 \mathrm{~cm}$ and 90 $\mathrm{cm}$ depth for the ambient plot. For the observations the error bars of the $95 \%$ confidence interval are included.

assuming steady state conditions, the conditions specified for 1980 were assumed to be in steady state.

\section{Results}

FLUX-WEIGHTED ANNUAL AVERAGE SOIL SOLUTION CONCENTRATIONS

\section{Ambient plot}

At $10 \mathrm{~cm}$ depth, both models predicted higher $\mathrm{NH}_{4}-$ concentrations than the upper limit of the confidence interval of the observations (Fig. 1). The overestimation by SMART 2, however, is much larger than by NUCSAM. At $90 \mathrm{~cm}$ depth, both models simulate very low $\mathrm{NH}_{4}-$ concentrations. Conversely, higher $\mathrm{NO}_{3}$ concentrations were simulated at $90 \mathrm{~cm}$ than at $10 \mathrm{~cm}$ depth. This is a usual pattern in dry systems. The observations, however, showed slightly higher $\mathrm{NO}_{3}$ concentrations at $10 \mathrm{~cm}$ depth than at $90 \mathrm{~cm}$ depth. At $10 \mathrm{~cm}$ depth, both models predicted comparable $\mathrm{NO}_{3}$ concentrations. The main difference between the models was the calculated $\mathrm{NO}_{3}$ to $\mathrm{NH}_{4}$ ratio. Due to higher nitrification fluxes in the top $10 \mathrm{~cm}$ (Table 1), NUCSAM calculated a higher $\mathrm{NO}_{3}$ to $\mathrm{NH}_{4}$ ratio than SMART 2, which in turn resulted in a higher calculated acid load. At $90 \mathrm{~cm}$ depth, both models predicted comparable $\mathrm{NO}_{3}$ concentrations, except for 1992 where SMART 2 estimated a higher $\mathrm{NO}_{3}$ concentration than NUCSAM. The total $\mathrm{N}$ leaching for both depths calculated by SMART 2 was clearly higher than the calculated N leaching by NUCSAM, which originated from higher calculated mineralization fluxes by SMART 2, due to higher calculated $\mathrm{pH}$ values. 
Table 1. Calculated annual average fluxes for 1992-1994 at $10 \mathrm{~cm}$ depth at the ambient site with NUCSAM and SMART 2 $\left(\mathrm{kmol}_{\mathrm{c}} \cdot \mathrm{ha}^{-1}\right)$.

\begin{tabular}{|c|c|c|c|c|c|c|}
\hline & & $\mathrm{SO}_{4}$ & $\mathrm{NO}_{3}$ & $\mathrm{NH}_{4}$ & $\mathrm{BC}^{2+}$ & Al \\
\hline \multirow[t]{2}{*}{ Throughfall } & NUCSAM & 1.67 & 0.70 & 2.36 & 0.70 & - \\
\hline & SMART 2 & 1.67 & 0.70 & 2.36 & 0.70 & - \\
\hline \multirow[t]{2}{*}{ Mineralization } & NUCSAM & - & - & 2.35 & 0.58 & - \\
\hline & SMART 2 & - & - & 3.58 & 0.89 & - \\
\hline \multirow[t]{2}{*}{ Nitrification } & NUCSAM & - & 2.71 & -2.71 & - & - \\
\hline & SMART 2 & - & 2.01 & -2.01 & - & - \\
\hline \multirow{2}{*}{ Weathering } & NUCSAM & - & - & - & 0.01 & 0.79 \\
\hline & SMART 2 & - & - & - & 0.01 & 0.52 \\
\hline Exchange/ & NUCSAM & 0.08 & - & -0.17 & 0.15 & 0.54 \\
\hline Adsorption ${ }^{1}$ & SMART 2 & 0.06 & - & - & -0.81 & $0.00^{2}$ \\
\hline \multirow[t]{2}{*}{ Root uptake } & NUCSAM & -0.23 & -0.70 & -1.06 & 0.40 & - \\
\hline & SMART 2 & - & -0.44 & -1.39 & 0.47 & - \\
\hline \multirow[t]{2}{*}{ Denitrification } & NUCSAM & - & -0.00 & - & - & - \\
\hline & SMART 2 & - & -0.01 & - & - & - \\
\hline \multirow{2}{*}{ Leaching } & NUCSAM & -1.82 & -2.74 & -0.77 & 1.01 & -1.33 \\
\hline & SMART 2 & -1.76 & -2.29 & -2.56 & 0.28 & -0.42 \\
\hline
\end{tabular}

${ }^{1}$ Positive value means desorption

2 Averaged value is zero

At $90 \mathrm{~cm}$ depth, SMART 2 matched the base cation concentrations closely, whereas NUCSAM overestimated. NUCSAM calculated much higher concentrations of $\mathrm{BC}^{2+}$ than SMART 2 at both depths. At $10 \mathrm{~cm}$ depth NUCSAM predicted the base cation concentrations well, while SMART 2 underestimated the base cation concentrations. The large difference in base cation concentrations at both depths was caused by the difference in cation exchange probably caused by higher $\mathrm{H}^{+}$and $\mathrm{Al}$ concentrations in NUCSAM compared to SMART 2 due to higher nitrification. NUCSAM calculated a discharge of base cations for $10 \mathrm{~cm}$ as well as for $90 \mathrm{~cm}$ depth whereas SMART 2 calculated a recharge of the complex at both depths.

Both models predict comparable $\mathrm{SO}_{4}$ concentrations at $10 \mathrm{~cm}$ and $90 \mathrm{~cm}$ depth (Fig. 2), within the confidence interval of the observations. A slight difference was caused by the root uptake, which is included in NUCSAM, whereas SMART 2 does not include $\mathrm{SO}_{4}$ in nutrient cycling.

Both models underestimated $\mathrm{Al}$ concentrations at $10 \mathrm{~cm}$ depth. SMART 2 predicted lower Al concentrations than NUCSAM, resulting in an overestimation of $\mathrm{pH}$ at $10 \mathrm{~cm}$ depth by SMART 2 and a good prediction of $\mathrm{pH}$ by NUCSAM. The overestimation of $\mathrm{pH}$ at $10 \mathrm{~cm}$ depth by SMART 2 is due mainly to a difference in nitrification fluxes at $10 \mathrm{~cm}$ depth. The overestimation of the $\mathrm{NH}_{4}$ concentration by SMART 2 causes the acid input to be lower, which in turn leads to lower $\mathrm{Al}$ concentrations and higher $\mathrm{pH}$. At $90 \mathrm{~cm}$ depth both models predicted comparable concentrations of $\mathrm{Al}$ and $\mathrm{pH}$, but NUCSAM underestimates $\mathrm{Al}$ concentrations at $90 \mathrm{~cm}$ depth, although pH was predicted well by NUCSAM at this depth. SMART 2 predicts a higher acid load due to a higher mineralization flux, which caused the higher leaching flux of Al calculated by SMART 2 . Another reason for different calculated leaching fluxes is the difference in weathering rates and discharge or recharge of the adsorption complex. This was caused by different weathering rates and GainesThomas constants used in NUCSAM and SMART 2.

\section{Pristine plot}

As a result of the reduction in throughfall, both models predicted lower $\mathrm{NO}_{3}, \mathrm{Al}$ and $\mathrm{SO}_{4}$ concentrations and a higher $\mathrm{pH}$ (Figs. 3 and 4). In general, the simulations differed in the same way as with the ambient plot. SMART 2 calculated a greater overestimation of the $\mathrm{NH}_{4}$ concentrations at $10 \mathrm{~cm}$ depth than NUCSAM. At $90 \mathrm{~cm}$ depth, both models predicted low $\mathrm{NH}_{4}$ concentrations. Both models predicted comparable $\mathrm{NO}_{3}$ concentrations, which were within the $95 \%$ confidence interval. The predictions of the base cation concentrations were the same as at the ambient plot: at $10 \mathrm{~cm}$ depth, SMART 2 underestimates and a closer prediction is given by NUCSAM. At $90 \mathrm{~cm}$ depth, NUCSAM overestimated BC concentrations, while SMART 2 predicted concentrations that were comparable with observation.

NUCSAM and SMART 2 predicted comparable $\mathrm{SO}_{4}$ concentrations. Both models, however, clearly underestimated the $\mathrm{SO}_{4}$ concentration. The same is true for the $\mathrm{Al}$ concentrations at both depths. This means that the models predicted a faster reduction in $\mathrm{Al}$ and $\mathrm{SO}_{4}$ concentra- 
$10 \mathrm{~cm}$
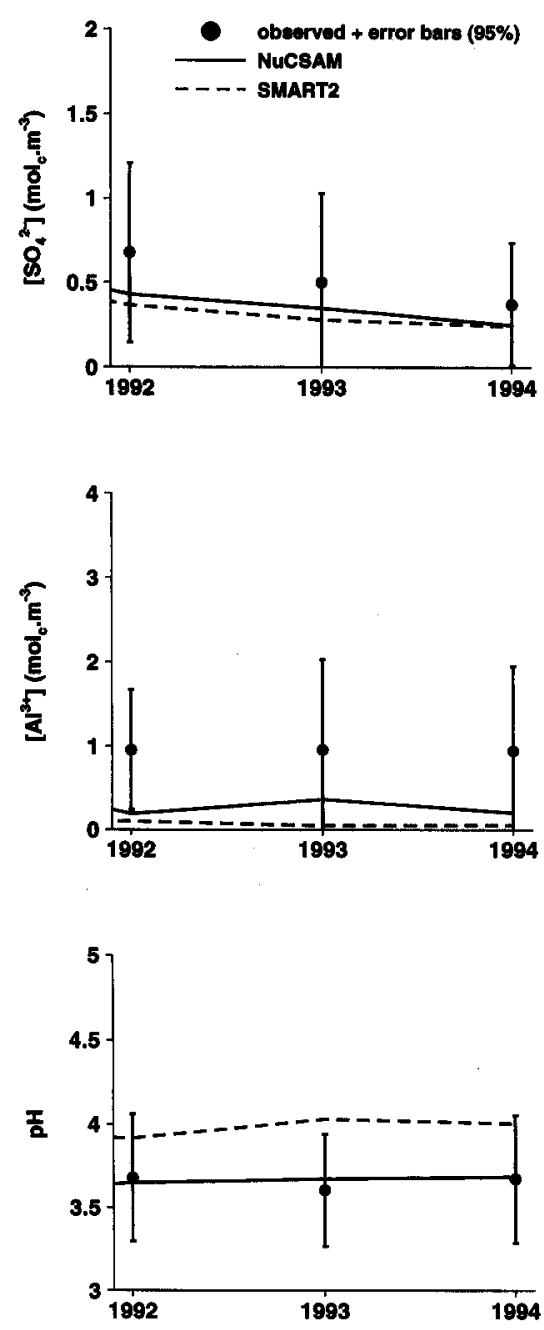

$90 \mathrm{~cm}$
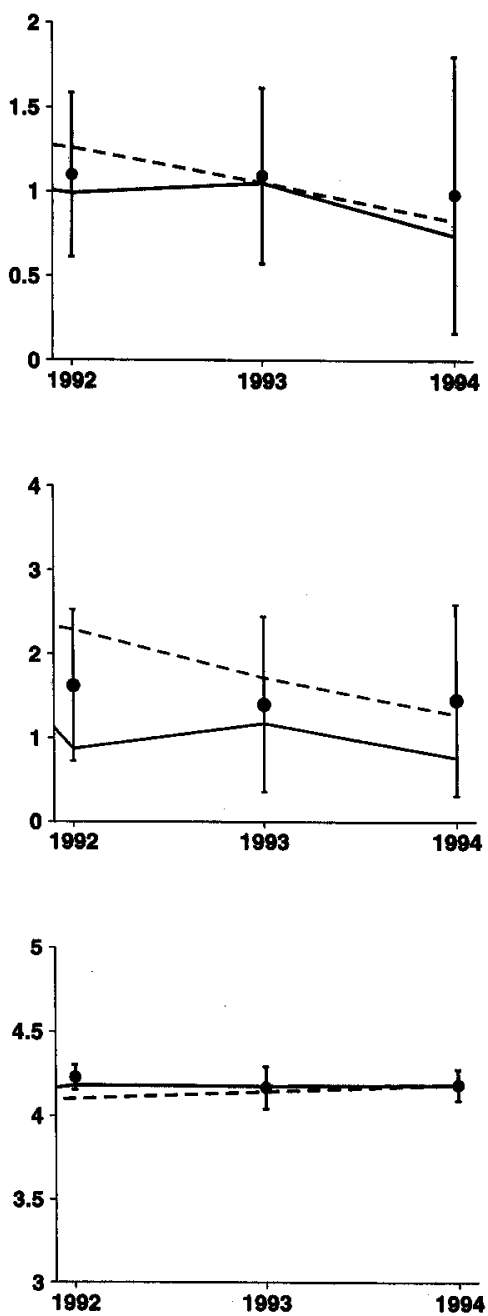

Fig. 2. Simulated and observed flux-meighted annual average concentrations of $\mathrm{SO}_{4}^{2-}, \mathrm{Al}^{3+}$ and $\mathrm{pH}$ at $10 \mathrm{~cm}$ and $90 \mathrm{~cm}$ depth for the ambient plot. For the observations the error bars of the $95 \%$ confidence interval are included.

tions than were observed. This may be caused by an underestimation of the $\mathrm{SO}_{4}$ adsorption capacity, which in turn resulted in an overestimation of the reduction in $\mathrm{SO}_{4}$ concentration. The $\mathrm{pH}$ at $10 \mathrm{~cm}$ depth showed a profound difference between both models. SMART 2 overestimated $\mathrm{pH}$ in response to the abrupt reduction of throughfall and underestimated nitrification rate. At $90 \mathrm{~cm}$ both models calculated comparable $\mathrm{pH}$.

\section{MEASURED AND MODELLED RESPONSES TO DEPOSITION REDUCTION}

The modelled and observed responses at the ambient and pristine site were compared by using modelled and observed percentage reductions in the flux-weighted concentrations (Fig. 5). With respect to relative changes of leaching fluxes at both depths, both models reacted com- parably to reductions in deposition. At $10 \mathrm{~cm}$ depth, the predicted response to throughfall reduction was larger than that at $90 \mathrm{~cm}$ depth which is consistent because of the smoothing effect with depth. Due to processes in the soil e.g. cation exchange, weathering, $\mathrm{SO}_{4}$ sorption, (de)nitrifcation and transport, the effect of throughfall reduction on the concentrations below the root zone is delayed. The reduction of $\mathrm{SO}_{4}$ concentrations shows this damping effect very clearly, both in observations and simulations. At 90 cm depth the reduction is smaller than at $10 \mathrm{~cm}$ depth, for the simulations as well as for the observations. Both models predict this reduction similarly, but faster than the observed changes, especially for $\mathrm{Al}$ and $\mathrm{SO}_{4}$. This may be caused by too small a $\mathrm{SO}_{4}$ adsorption capacity (see previous section). SMART 2 predicted the reduction of Al concentration at both depths slightly faster than NUCSAM and the observations. The faster response of $\mathrm{SO}_{4}$ and $\mathrm{Al}$ in 
$10 \mathrm{~cm}$
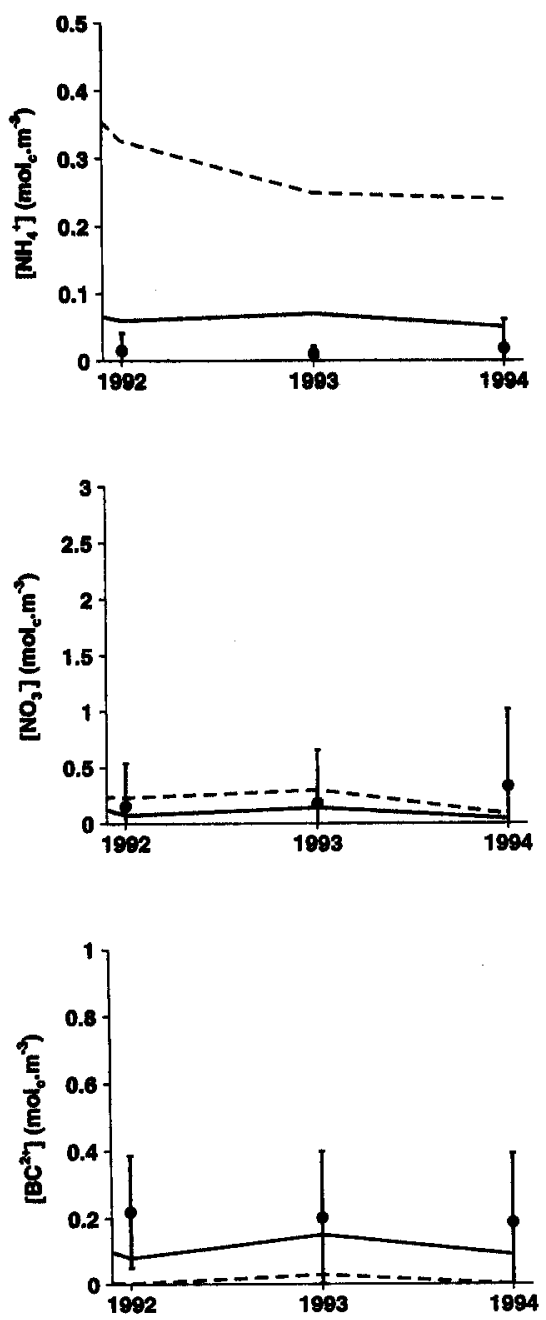

$90 \mathrm{~cm}$
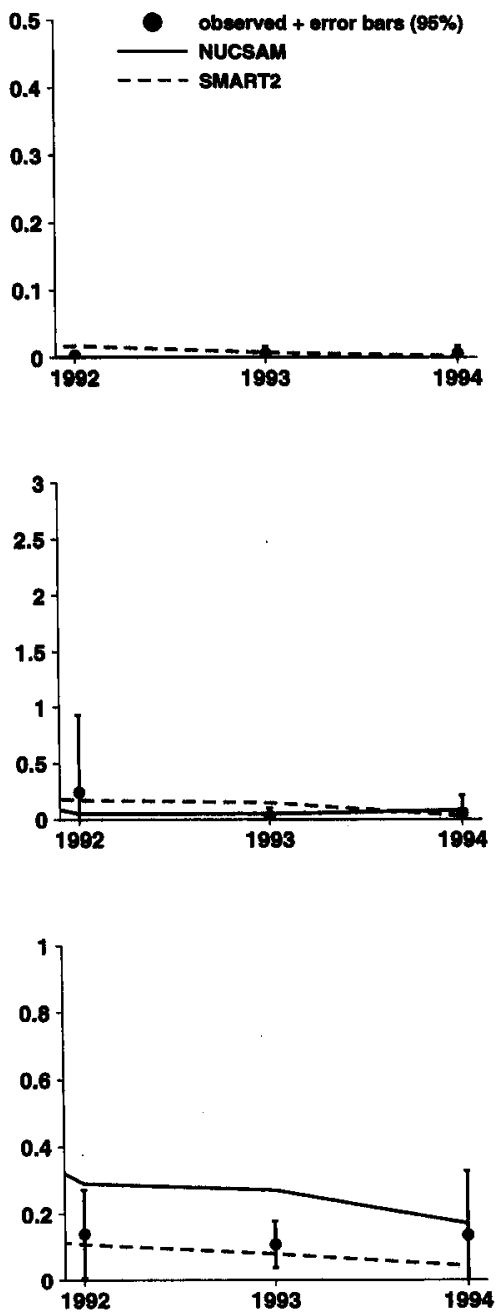

Fig. 3. Simulated and observed flux-peighted annual average concentrations of $\mathrm{NH}_{4}^{+}, \mathrm{NO}_{3}{ }^{-}$and $\mathrm{BC}^{2+}\left(\mathrm{Ca}^{2+}+\mathrm{Mg}^{2+}\right)$ at $10 \mathrm{~cm}$ and 90 cm depth for the pristine plot. For the observations the error bars of the $95 \%$ confidence interval are included.

1992 simulated by SMART 2 was due to the aggregation of the mineral soil layer into one layer. For a more realistic simulation of the progression of the de-acidification front with depth, more layers must be included. This effect is shown clearly by Van der Salm et al. (1995); they compared a one compartment model with two multi-layer models. At $10 \mathrm{~cm}$ depth, NUCSAM calculated a higher reduction in N concentrations than SMART 2, but, at $\mathbf{9 0}$ cm depth, SMART 2 calculated slightly more reduction. The observed reductions were similar to the NUCSAM simulations, especially during the last two years. The reduction of base cation concentrations was overestimated by both models at $10 \mathrm{~cm}$ depth, whereas at $90 \mathrm{~cm}$ depth both models overestimated the effect of throughfall reduction only slightly. At $10 \mathrm{~cm}$ depth, SMART 2 predicted a much greater effect of acid deposition reduction on BC leaching. This difference originates mainly from a different behaviour of cation exchange (Tables 1 and 2).

\section{Discussion and conclusions}

Due to different $\mathbf{N}$ dynamics, large differences in model results were found at $10 \mathrm{~cm}$ depth, but at $90 \mathrm{~cm}$ depth these differences were smaller. The differences in concentrations of $\mathrm{NO}_{3}, \mathrm{NH}_{4}, \mathrm{Al}$ and $\mathrm{pH}$ were caused mainly by the difference in mineralization fluxes and nitrification rates. There are two possible reasons for the high mineralization fluxes calculated by SMART 2 . SMART 2 predicted values of $\mathrm{pH}$ which were too high and this led to a lower reduction in mineralization. Large reductions in acid deposition lead to high $\mathrm{pH}$ values in SMART 2. The other reason can be found in the calibration of the mineralization rate to the amount of litter calculated by NUCSAM (Van der Salm et al., this issue). The fact that the litter amounts were modelled satisfactorily does not necessarily mean that this is also true for the $\mathrm{N}$ mineralization flux. A calibration of the mineralization rate directly to the $\mathrm{N}$ min- 
$10 \mathrm{~cm}$
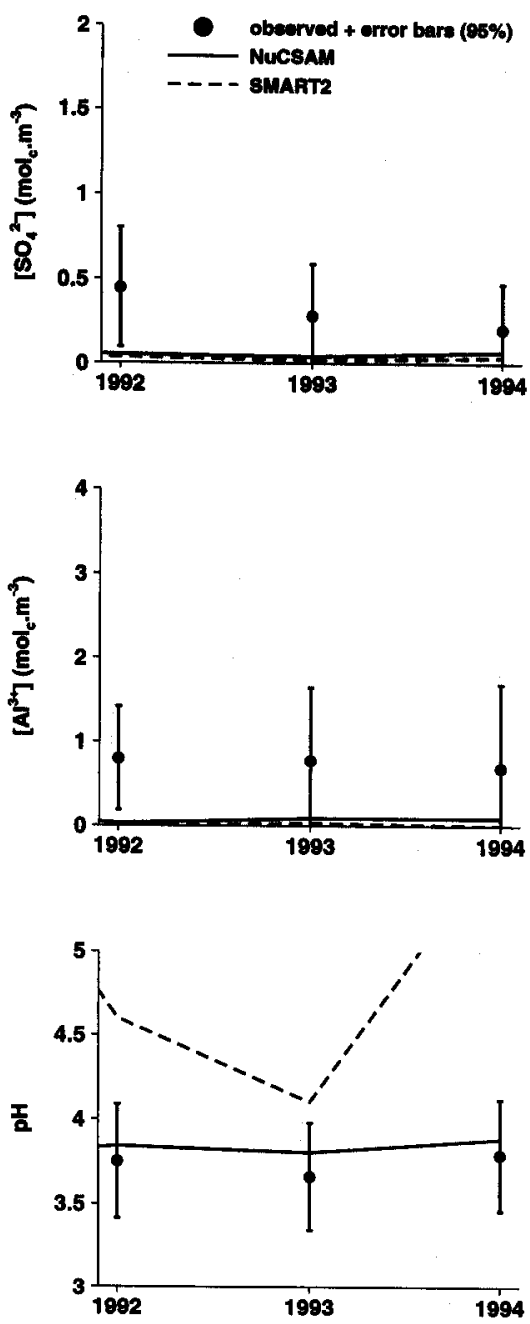

$90 \mathrm{~cm}$
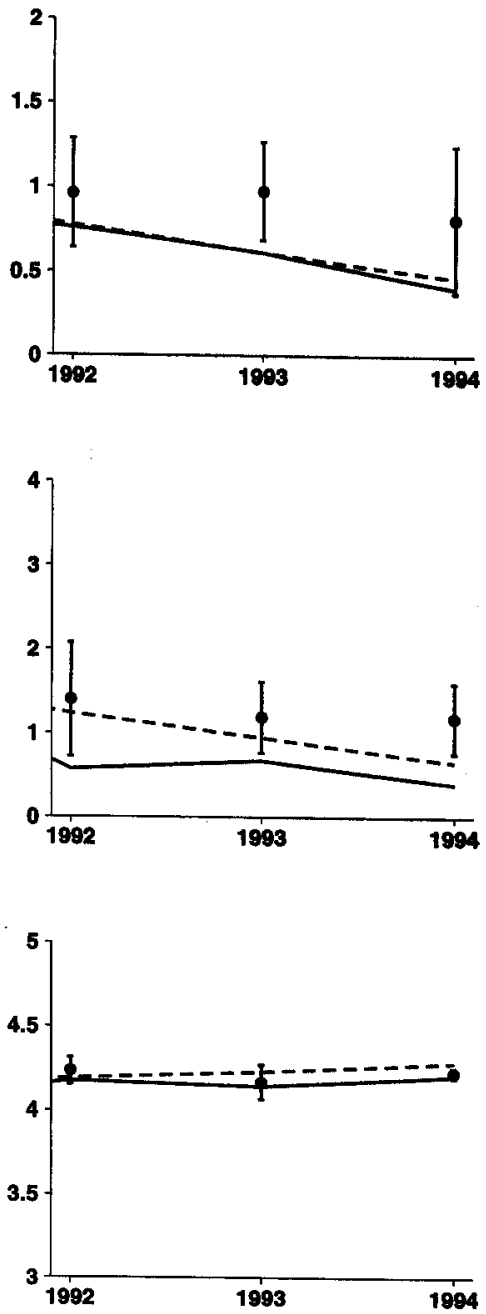

Fig. 4. Simulated and observed flux-meighted annual average concentrations of $\mathrm{SO}_{4}{ }^{2-}, \mathrm{Al}^{3+}$ and $\mathrm{pH}$ at $10 \mathrm{~cm}$ and $90 \mathrm{~cm}$ depth for the pristine plot. For the observations the error bars of the $95 \%$ confidence interval are included.

eralization fluxes in NUCSAM would probably give more satisfactory results. Furthermore, the differences in nitrification rates were related directly to the differences in mineralization fluxes. Consequently, it can be concluded that more attention has to be paid to the input mapping focussing on $\mathrm{N}$ dynamics. High mineralization fluxes imply high nitrification fluxes. Besides that, these results emphasise the need to modify the description of processes related to N-dynamics in SMART 2.

At $10 \mathrm{~cm}$ depth, NUCSAM predicts $\mathrm{NO}_{3}$ and $\mathrm{Al}$ concentrations better than SMART 2, although SMART 2 was extended to a two-layer model. At $90 \mathrm{~cm}$ depth, SMART 2 predicts the $\mathrm{NO}_{3}$ and $\mathrm{Al}$ concentrations quite well and it seems that for the root zone as a whole a model with only two layers provides adequate results. Large differences were found between the predicted concentrations of BC with SMART 2 and NUCSAM. These differences were probably caused by the derivation of exchange constants and weathering rates. Although for both models the constants were derived from observations, both models predicted different $\mathrm{BC}$ concentrations.

In general, the effect of reduction of acid deposition is greater at $10 \mathrm{~cm}$ depth than at $90 \mathrm{~cm}$ depth due to different soil processes. The model predictions are compared to flux-weighted annual averaged observed concentrations, neglecting the intra-arrival variability. Both models predict effects of acid deposition reduction on soil solution concentrations in the same direction. SMART 2 overestimates the effect of deposition reduction on $\mathrm{SO}_{4}$ and $\mathrm{Al}$ concentrations due to the aggregation of the mineral soil into one layer. The effect on $\mathrm{N}$ concentrations is predicted well by SMART 2 whereas NUCSAM underestimates the effect on $\mathrm{N}$ concentrations. Both models predict a faster effect on $\mathrm{SO}_{4}$ concentrations than observed and this may be cor- 
Al

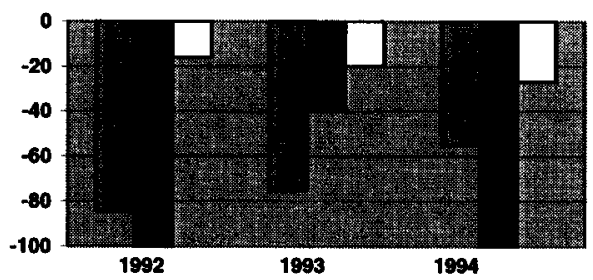

$\mathrm{SO}_{4}$

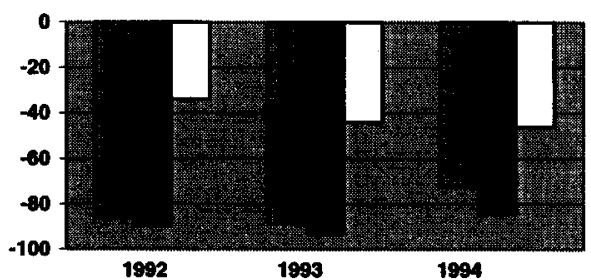

$\mathbf{N}$

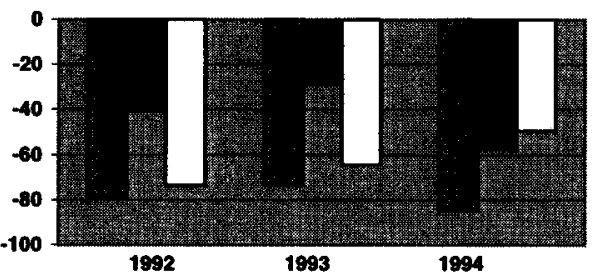

$\mathrm{BC}^{2+}$

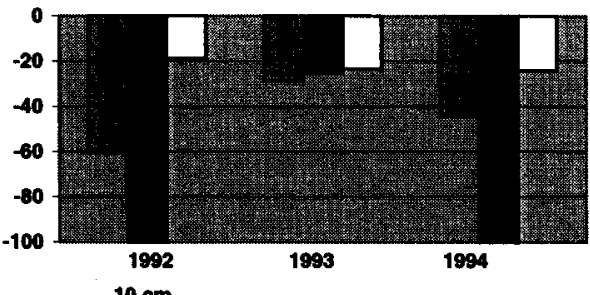

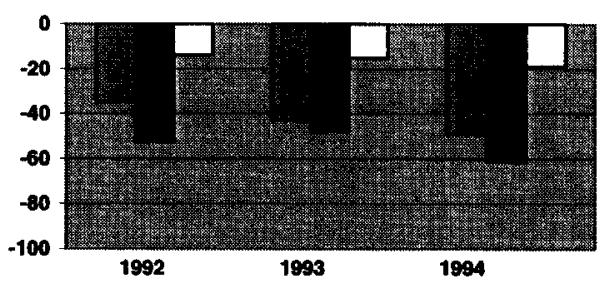
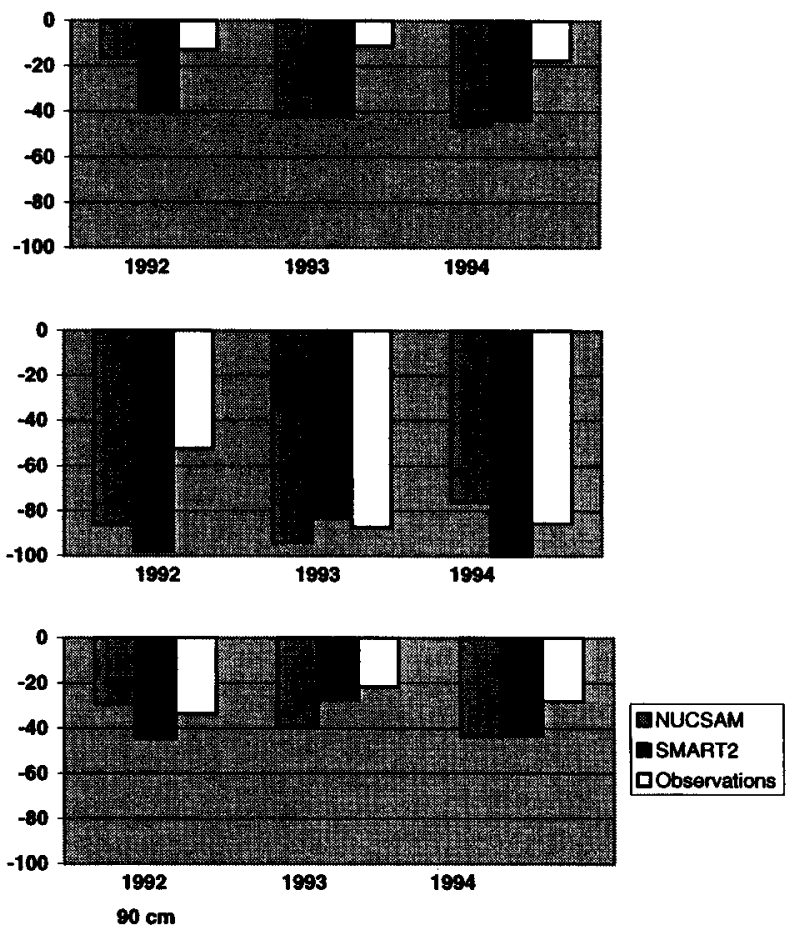

Fig. 5. Predicted and observed relative effect (\%) of throughfall reduction on $\mathrm{Al}^{3+}, \mathrm{SO}_{4}^{2-}, \mathrm{N}$ and $\mathrm{BC}^{2+}$ concentrations to the roofed ambient plot at 10 and $90 \mathrm{~cm}$ depth.

Table 2. Calculated annual average fluxes for $1992-1994$ at $90 \mathrm{~cm}$ depth at the ambient site with NUCSAM and SMART 2 $\left(\mathrm{kmol}_{\mathrm{c}} \cdot \mathrm{ha}^{-1}\right)$.

\begin{tabular}{|c|c|c|c|c|c|c|}
\hline & & $\mathrm{SO}_{4}$ & $\mathrm{NO}_{3}$ & $\mathrm{NH}_{4}$ & $\mathrm{BC}^{2+}$ & $\mathrm{Al}$ \\
\hline \multirow{2}{*}{ Throughfall } & NUCSAM & 1.67 & 0.70 & 2.36 & 0.70 & - \\
\hline & SMART 2 & 1.67 & 0.70 & 2.36 & 0.70 & - \\
\hline \multirow[t]{2}{*}{ Mineralization } & NUCSAM & - & - & 3.48 & 0.95 & - \\
\hline & SMART 2 & - & - & 4.87 & 1.21 & - \\
\hline \multirow[t]{2}{*}{ Nitrification } & NUCSAM & - & 2.80 & -2.80 & - & - \\
\hline & SMART 2 & - & 2.75 & -2.75 & - & - \\
\hline \multirow[t]{2}{*}{ Weathering } & NUCSAM & 一 & - & - & 0.01 & 2.80 \\
\hline & SMART 2 & - & - & - & 0.22 & 4.66 \\
\hline Exchange/ & NUCSAM & 0.80 & - & -0.28 & 0.91 & -0.22 \\
\hline Adsorption ${ }^{1}$ & SMART 2 & 1.03 & - & - & -0.31 & -0.05 \\
\hline \multirow[t]{2}{*}{ Root uptake } & NUCSAM & -0.78 & -2.14 & -3.14 & -1.55 & - \\
\hline & SMART 2 & - & -1.42 & -4.46 & -1.53 & - \\
\hline \multirow[t]{2}{*}{ Denitrification } & NUCSAM & - & -0.00 & - & - & - \\
\hline & SMART 2 & - & -0.02 & - & - & - \\
\hline \multirow[t]{2}{*}{ Leaching } & NUCSAM & -2.62 & -1.41 & -0.02 & -1.08 & -2.67 \\
\hline & SMART 2 & -2.93 & -2.37 & -0.03 & -0.32 & -5.04 \\
\hline
\end{tabular}

\footnotetext{
1 Positive value means desorption
} 
rected by higher $\mathrm{SO}_{4}$ adsorption capacity. To predict, adequately, the changes in leaching fluxes due to throughfall reduction these processes in the models should be modified.

SMART 2 simulates flux-weighted annual averaged soil solution concentrations satisfactorily. The predicted concentrations are comparable with NUCSAM predictions as well as with observation. Van der Salm et al. (1995) showed satisfactory results with SMART 2 for a longer observation period, which contributes to an increase in confidence in using SMART 2 at the regional scale.

\section{References}

Alewell, C., Bredemeier, M., Matzner, E. and Blanck, K., 1997. Soil solution response to experimentally reduced acid deposition in a forest ecosystem. 7. Environ. Qual., 26, 658-665.

Beier, C., Hultberg, H., Moldan, F. and Wright, R.F., 1985. MAGIC applied to roof experiments (Risdalsheia, N; Gårdsjön, S: Klosterhede, DK) to evaluate the rate of reversibility of acidification following experimentally reduced acid deposition. Wat. Air Soil Pollut., 85, 1745-1751.

Belmans, C., Wesseling, J.G. and Feddes, R.A., 1983. Simulation model of the water balance of a cropped soil providing different types of boundary conditions: SWATRE. F. Hydrol., 63, 27-286.

Boxman, A.W., Van Dam, D., Van Dijk, H.F.G., Hogervorst, R.F. and Koopmans, C.J., 1995. Ecosystem responses to reduced nitrogen and sulphur inputs into two coniferous forest stands in the Netherlands. For. Ecol. Manage., 71, 7-29.

Cosby, B.J., Wright, R.F. and Gjessing, E., 1995. An acidification model (MAGIC) with organic acids evaluated using whole-catchment manipulations in Norway. F. Hydrol., 170, 101-122.

De Vries, W., Kros, J., van der Salm, C., Groenenberg, J.E. and Reinds, G.J., 1998. The use of upscaling procedures in the application of soil acidification models at different spatial scale, Nutrient Cycling in Agroecosystems, 50, 223-236.

De Vries, W., Posch, M. and Kämäri, J., 1989. Simulation of the long-term sod response to acid deposition in various buffer ranges. Wat. Air Soil Pollut., 48, 349-390.
Giesler, R., Moldan, F., Lundström, U. and Hultberg, H., 1996. Reserving acidification in a forested catchment in Southwestern Sweden: Effects on soil solution chemistry. 7 . Environ. Qual., 25, 110-119.

Groenenberg, J.E., Kros, J., Van der Salm, C. and De Vries, W., 1995. Application of the model NUCSAM to the Solling spruce site. Ecol. Model., 83, 97-107.

Kros, J., Reinds, G.J., de Vries, W., Latour, J.B. and Bollen, M.J.S., 1995a. Modelling of soil acidity and nitrogen availability in natural ecosystems in response to changes in acid deposition and hydrology. Report 95. Winand Staring Centre for Integrated Land, Soil and Water Research, Wageningen.

Kros, J., Groenenberg, J.E., de Vries, W. and van der Salm, C., $1995 \mathrm{~b}$. Uncertainty due to time resolution in long term predictions of forest soil acidification. Wat. Air Soil Pollut., 79, 353-375.

Rose, K.A., Cook, R.B., Brenkert, A.L., Gardner R.H. and Hettelingh, J.P., 1991. 'Systematic comparison of ILWAS, MAGIC and ETD watershed acidification models. 1. Mapping among model inputs and deterministic results.' Wat. Resour. Res., 27, 2577-2589.

Tiktak, A., Van Grinsven, J.J.M., Groenenberg, J.E., Van Heerden, C., Janssen, P.H.M., Kros, J., Mohren, G.M.J., Van der Salm, C., Van de Veen, J.R. and De Vries, W., 1995. Application of three forest-soil-atmosphere models to the Speuld experimental forest. RIVM, report no. 733001003, Bilthoven, the Netherlands, 95 pp.

Van der Salm, C, Kros, J., Groenenberg, J.E., de Vries, W. and Reinds, G.J., 1995. Application of soil acidification models with different degrees of process description (SMART, RESAM and NUCSAM) on an intensively monitored spruce site. In: Solute Modelling in Catchment Systems (S.T. Trudgill (Ed.)). Wiley, Chichester, UK.

Van der Salm, C., Groenenberg, J.E. and Boxman, A.W., 1998. Modelling the response of soil and soil solution chemistry upon roofing a forest in a high nitrogen deposition area. Hydrol. Earth System Sci., 2, 451-471.

Wright, R.F., Cosby, B.J., Flaten, M.B. and Reuss, J.O., 1990. Evaluation of an acification model with data from manipulated catchments in Norway, Nature, Lond. 343, 1185-1186. 